Relations industrielles

Industrial Relations

\title{
Hommage à Jack Barbash, 1911-1994
}

\section{Jean Sexton}

Volume 49, numéro 3, 1994

URI : https://id.erudit.org/iderudit/050952ar

DOI : https://doi.org/10.7202/050952ar

Aller au sommaire du numéro

\section{Éditeur(s)}

Département des relations industrielles de l'Université Laval

\section{ISSN}

0034-379X (imprimé)

1703-8138 (numérique)

Découvrir la revue

\section{Citer ce document}

Sexton, J. (1994). Hommage à Jack Barbash, 1911-1994. Relations industrielles / Industrial Relations, 49(3), 440-440. https://doi.org/10.7202/050952ar

Tous droits réservés @ Département des relations industrielles de l'Université Laval, 1994
Ce document est protégé par la loi sur le droit d'auteur. L’utilisation des services d'Érudit (y compris la reproduction) est assujettie à sa politique d'utilisation que vous pouvez consulter en ligne.

https://apropos.erudit.org/fr/usagers/politique-dutilisation/ 


\section{HOMMAGE À JACK BARBASH \\ 1911-1994}

Un autre pionnier des relations industrielles en Amérique du Nord vient de nous quitter. Jack Barbash de l'Université du Wisconsin-Madison est décédé en mai dernier. Fervent supporteur, collaborateur efficace, ami fidèle de la revue Relations industrielles et de son directeur-fondateur Gérard Dion, et membre du Comité de rédaction depuis 1991, Jack a une feuille de route aussi impressionnante que diversifiée. En effet, celui-ci a connu trois carrières : d'abord, il a été économiste pour l'Amalgamated Meat Cutters Unions et pour le département des unions industrielles de l'AFL-CIO. Ensuite, il a œuvré dans la fonction publique pour le New York State Department of Labor, pour le National Labor Relations Board, pour le U.S. Office of Education, pour le War Production Board et finalement, pour le U.S. Senate Committee on Labor. En 1957, Jack devenait professeur d'université.

Son implication dans le domaine des relations industrielles dépasse largement les États-Unis. En plus d'avoir contribué à la fondation de l'Association internationale des relations professionnelles (AIRP) en 1966 et d'avoir siégé à son comité exécutif, on le retrouve en Europe, en Amérique du Sud, en Asie, en Australie, en plus d'agir comme consultant pour le BIT, l'OCDE et le Ministère du travail du Brésil.

Jack a également été président de l'Industrial Relations Research Association (USA) en 1980 et il a fondé et présidé le groupe de travail de l'AIRP sur la théorie des relations industrielles. Il a beaucoup écrit et ses travaux ont été traduits en plusieurs langues dont le français, l'allemand et l'espagnol. Deux de ses ouvrages m'ont surtout marqué : Practice of Unionism (1956) et Elements of Industrial Relations (1984). Son style concis et précis reflétait une pensée claire et profonde sur la nature même des relations industrielles.

Jack était un être profondément simple, sympathique et attachant. Il croyait à l'importance des valeurs et, dans ses derniers écrits, dénonçait la presque totale absence de préoccupations de nature philosophique dans le domaine des relations industrielles.

À son épouse Kate qui l'a toujours accompagné et secondé et à sa famille, mes collègues et moi offrons notre plus profonde sympathie.

Jean SExton

Directeur

Revue Relations industrielles 